\title{
Long-Term Mortality in Patients with Positive Lymph Nodes at the Time of Radical Prostatectomy
}

\author{
Michael Froehner ${ }^{a} \quad$ Rainer Koch $^{b}$ Samaneh Farahzadi ${ }^{a} \quad$ Ulrike Heberling $^{a}$ \\ Angelika Borkowetz $^{a}$ Lars Twelker ${ }^{a, d}$ Gustavo B. Baretton ${ }^{c}$ Manfred P. Wirth ${ }^{a}$ \\ Christian Thomas ${ }^{\mathrm{a}}$ \\ a Department of Urology, University Hospital "Carl Gustav Carus", Technische Universität Dresden, Dresden, Germany; \\ ${ }^{b}$ Department of Medical Statistics and Biometry, University Hospital "Carl Gustav Carus", Technische Universität

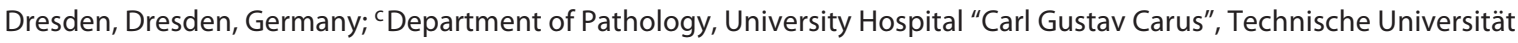 \\ Dresden, Dresden, Germany; ${ }^{\mathrm{d}}$ Department of Urology, Franziskus Hospital, Bielefeld, Germany
}

\section{Keywords}

Prostate cancer - Radical prostatectomy - Lymph node dissection - Positive lymph nodes - Lymph node density .

Gleason score $\cdot$ Mortality

\begin{abstract}
Background: The aim of this study was to determine prognostic factors and to provide long-term mortality data in patients with positive lymph nodes at the time of radical prostatectomy in a sample with long-term follow-up. Methods: A total of 527 patients with complete data sets treated in the years 1992-2014 were studied. The median follow-up was 7.2 years. The median number of removed lymph nodes was 15. Age, year of surgery, Gleason score, local tumor stage, prostate-specific antigen level, lymph node density, lymph node count and the number of positive lymph nodes were included in multivariable competing risk analyses with prostate cancer mortality as endpoint. Results: After 20 years, $28 \%$ of patients $(95 \% \mathrm{Cl} 20-36 \%$ ) died from non-prostate cancer (competing) causes, whereas $29 \%$ (95\% Cl 23-36\%) died from prostate cancer. Only lymph node density (strati-
\end{abstract}

\section{KARGER}

(C) 2019 S. Karger AG, Basel

E-Mail karger@karger.com

www.karger.com/uin fied by the median of $11.1 \%$; hazard ratio [HR] $1.66,95 \% \mathrm{Cl}$ $1.04-2.64, p=0.0340$ ) and Gleason score (8-10 vs. $<8$ : HR $5.97,95 \% \mathrm{Cl} 3.18-11.23, p<0.0001$ ) were independent predictors of prostate cancer mortality. Patients with a Gleason score $<8$ and a lymph node density $<$ median had a 20-year prostate cancer mortality of only $5 \%(95 \% \mathrm{Cl} 0-10 \%)$, whereas this rate in patients with Gleason score 8-10 and a lymph node density $\geq$ median was $44 \%(95 \% \mathrm{Cl} 32-56 \%), p<0.0001$. Conclusions: Mortality in patients with positive lymph nodes was determined by tumor aggressiveness and the relative extent of spread; neither the year of surgery nor the number of removed lymph nodes was associated with outcome. Patients with a lymph node density of $<11.1 \%$ and a Gleason score $<8$ had an excellent long-term outcome.

๑ 2019 S. Karger AG, Basel

\section{Introduction}

The presence of positive lymph nodes at radical prostatectomy is associated with increased mortality from prostate cancer $[1,2]$. Although current guidelines rec- 
ommend extended lymph node dissection in intermediate and high-risk patients $[1,3]$, a survival benefit of a more extensive lymph node dissection in patients with positive lymph nodes has not yet been demonstrated [35]. Moreover, studies investigating outcome in those patients are limited by short follow-up $[4,6]$. The aim of this study was to determine prognostic factors and to provide long-term mortality data in patients with positive lymph nodes at the time of radical prostatectomy.

\section{Patients and Methods}

Out of 5,997 patients who consecutively underwent radical prostatectomy at our institution between December 1, 1992 and $31,2014,527$ patients with positive lymph nodes and complete data sets (date of birth, date of surgery, number of removed lymph nodes, number of positive lymph nodes, Gleason score, local tumor stage, prostate-specific antigen (PSA) level, application of neoadjuvant hormonal treatment) were analyzed. Institutional review board approval was obtained. The mean number of lymph nodes removed was 16 (median 15). The mean follow-up in the surviving patients was 8.5 years (median 7.2 years). The mean age was 65 years (median 66 years). The mean PSA level in patients who did not receive neoadjuvant hormonal treatment was $21.2 \mathrm{ng} /$ $\mathrm{mL}$ (median $13.6 \mathrm{ng} / \mathrm{mL}$ ). The mean number of removed lymph nodes was 16.2 (median 15.0). The mean number of positive lymph nodes was 2.5 (median 2.0). The mean lymph node density (positive lymph nodes per removed lymph nodes) was $16.6 \%$ (median $11.1 \%)$. The other patient characteristics are shown in Table 1.

Prostate cancer mortality (mortality in the presence of uncontrolled prostate cancer progression) was the study endpoint. Deaths from other or unknown causes (Table 1) were considered competing events. Follow-up data were collected from urologists, general practitioners, the patients, their relatives, the hospital information system, health insurance companies, local authorities, and the local tumor register. The causes of death were classified based on the available data by a senior clinician (M.F.). Age at surgery (continuous variable), year of surgery (continuous variable), Gleason score (8-10 vs. $<8$ ), local tumor stage (extracapsular disease versus organ confined), PSA level ( $\geq 10 \mathrm{ng} / \mathrm{mL}$ or neoadjuvant hormonal therapy versus $<10 \mathrm{ng} / \mathrm{mL}$ and no neoadjuvant hormonal treatment), lymph node density (number of involved lymph nodes per number of removed lymph nodes; $\geq$ median versus $<$ median), lymph node count (continuous variable), and the number of positive lymph nodes (continuous variable) were included in the multivariable analyses using proportional hazard models for competing risks. The analyses were performed with the Statistical Analysis Systems Version 9.4 statistical package (SAS Institute, Cary, NC, USA).

\section{Results}

The 10 -year prostate cancer mortality rate was $18 \%$ (95\% CI 14-22\%), whereas the 10-year competing mortality rate was $12 \%$ (95\% CI 9-16\%). After 20 years, the
Table 1. Demographic data of the study population

\begin{tabular}{lrc}
\hline Parameter & $\begin{array}{c}\text { Number of } \\
\text { patients, } n\end{array}$ & $\begin{array}{l}\text { Proportion, } \\
\%\end{array}$ \\
\hline Whole sample & 527 & 100 \\
Gleason score $<7$ & 24 & 4.6 \\
Gleason score 7 & 211 & 40.0 \\
Gleason score 8-10 & 292 & 55.4 \\
Organ confined disease & 97 & 18.4 \\
Extracapsular disease & 430 & 81.6 \\
Neoadjuvant hormonal treatment & 78 & 14.8 \\
No neoadjuvant hormonal treatment & 449 & 85.2 \\
Dead of prostate cancer & 81 & 15.4 \\
Dead of non-cancer causes & 37 & 7.0 \\
Dead of second cancers & 26 & 4.9 \\
Dead of unknown causes & 2 & 0.4 \\
\hline
\end{tabular}

estimated prostate cancer mortality rate was $29 \%$ (95\% CI 23-36\%), whereas the estimated competing mortality rate was $28 \%$ (95\% CI $20-36 \%)$. The 10 -year prostate cancer mortality rates were $13 \%$ (95\% CI $8-18 \%)$ in patients with 1 involved lymph node $(n=256,49 \%$ of sample), $14 \%$ (95\% CI 6-21\%) in patients with 2 involved lymph nodes ( $n=114,22 \%$ of sample), and $29 \%$ (95\% CI $20-37 \%)$ in patients with 3 or more involved lymph nodes ( $n=157,30 \%$ of sample). After 20 years, the estimated prostate cancer mortality rates were $21 \%$ (95\% CI $13-28 \%)$ in patients with 1 involved lymph node, $31 \%$ (95\% CI 6-56\%) patients with 2 involved lymph nodes, and $40 \%(95 \%$ CI $23-58 \%)$ in patients with 3 or more involved lymph nodes (Pepe-Mori test: 1 vs. 2 involved lymph nodes: $p=0.3954 ; 2$ vs. 3 or more involved lymph nodes: $p=0.0047$; Fig. $1 \mathrm{a})$. In the multivariable analyses, 2 parameters were identified as independent predictors of increased prostate cancer mortality: a Gleason score of 8-10 and a lymph node density above or equal to the median of $11.1 \%$ (Table 2). Stratification by these 2 parameters separated 3 balanced and distinctly different prognostic subgroups (high risk: Gleason score 8-10 and lymph node density $\geq$ median; intermediate risk Gleason score $8-10$ or lymph node density $\geq$ median; low risk Gleason score $<8$ and lymph node density $<$ median; Fig. 1b). The 10-year prostate cancer mortality rates were $3 \%$ (95\% CI $0-7 \%)$ in the low-risk group ( $n=135,26 \%$ of sample), $17 \%$ (95\% CI 11-24\%) in the intermediaterisk group ( $n=221,42 \%$ of sample), and $30 \%$ (95\% CI $22-38 \%)$ in the high-risk group ( $n=171,32 \%$ of sample). After 20 years, the estimated prostate cancer mortality rates were $5 \%$ (95\% CI $0-10 \%)$ in the low-risk group, $27 \%$ (95\% CI $16-38 \%)$ in the intermediate risk group, 
Fig. 1. Cumulative mortality from prostate cancer after stratification by the number of involved lymph nodes (a) and by the 2 dichotomized factors identified as independent predictors of prostate cancer mortality in the multivariable analyses (b).

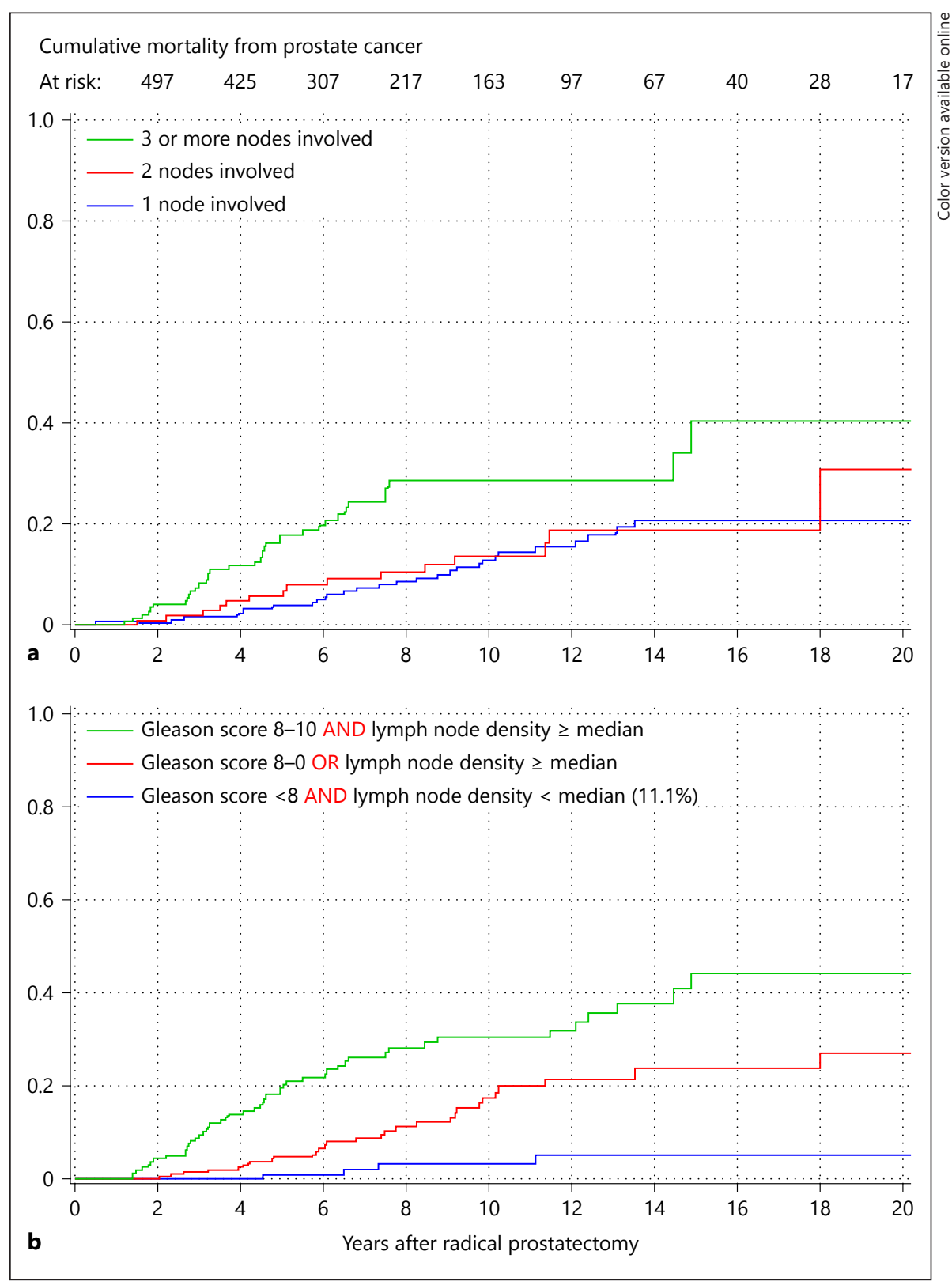

and $44 \%$ (95\% CI 32-56\%) in the high-risk group (Pepe Mori test: low risk versus intermediate risk group: $p=$ 0.0001 ; intermediate versus high-risk group: $p<0.0001$; Fig. 1b).

\section{Discussion}

Mortality in patients with positive lymph nodes is determined by tumor biology; neither the year of surgery nor the number of removed lymph nodes is associated with the outcome (Table 2). Patients with a lymph node density of $<11.1 \%$ and a Gleason score $<8$ had an excellent long-term outcome that was similar to an outcome that may be expected in patients with node-negative disease $[7,8]$.

As other authors [4], we found no impact of a removal of a higher number of lymph nodes in patients with positive lymph nodes on prostate cancer mortality. In the multivariable analyses, there was even a trend toward an increasing mortality risk with an increasing number of removed lymph nodes (Table 2) possibly reflecting an attempt to perform a 
Table 2. Full and optimal proportional hazard models for competing risks including possible predictors of prostate cancer mortality

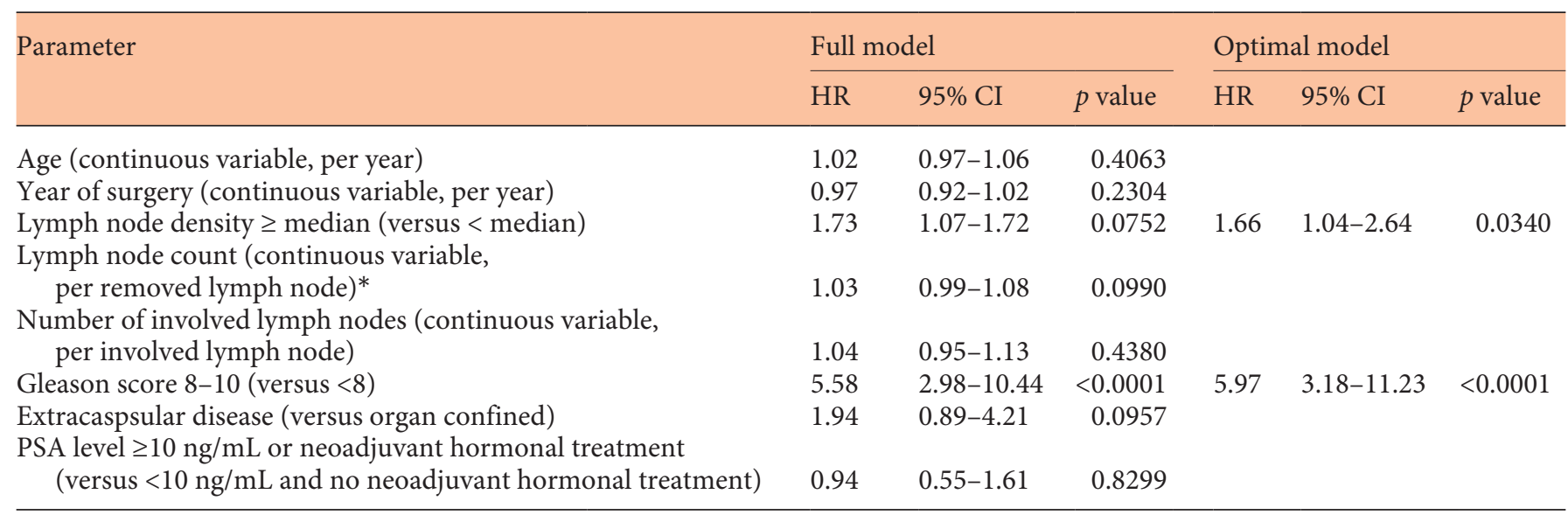

* In an optimal model containing Gleason score and lymph node density, this variable narrowly missed the significance level with an increasing risk with a higher number of removed lymph nodes (HR per removed node 1.03, 95\% CI 1.00-1.07, $p=0.0540$ ).

$\mathrm{HR}$, hazard ratio; PSA, prostate-specific antigen.

more extensive lymph node dissection in patients with gross lymph node metastases or with high-risk tumors [4].

Similar to observations by others [4], the number of involved lymph nodes alone did not separate subgroups with different prostate cancer mortality very clearly (Fig. 1).

In the multivariable analysis, the more powerful variable lymph node density (reflecting both the number of positive and the relative extent of spread) replaced the closely related variable number of involved lymph nodes (Table 2).

After stratification by the number of involved lymph nodes, the 20 -year prostate cancer mortality in the current study was substantially lower (1 positive node: $20 \mathrm{vs.}$ $45 \%$ [6], 2 positive nodes: 31 vs. $85 \%$ [6], 3 or more positive nodes: 40 vs. $87 \%$ [6]) than in a study in 88 patients with a median follow-up of 15.6 years treated between 1989 and 1999 [6]. Since in the current study there were fewer lymph nodes removed (mean number 16 vs. 21 [6]), more patients had a Gleason score of 8-10 (55 vs. 30\% [6]) and extracapsular disease (82 vs. 69\% [6]) and the median PSA level was higher $(13.6 \mathrm{ng} / \mathrm{mL}$ in patients without neoadjuvant hormonal treatment versus $11.9 \mathrm{ng} / \mathrm{mL}$ [5]). These differences may not be attributed to a more favorable risk profile. The late application of hormonal treatment not before symptomatic progression in the cited study [6] is a more likely explanation. We encouraged adjuvant hormonal treatment (and in recent years adjuvant radiotherapy as well) in the vast majority of patients with positive lymph nodes. In an earlier analysis in pa- tients treated between 1992 and 2005, 70\% of patients received hormonal treatment within 3 months and 93\% within 1 year after surgery [9]. Adjuvant hormonal treatment may be associated with a decreased prostate cancer mortality rate in this population [10] that was similar to that seen in our study. Compared with a cohort of 505 patients treated between 1982 and 2011 [11], in our sample a lower 20 -year prostate cancer mortality rate (29 vs. $60 \%$ [11]) was seen, possibly again because of the low use of adjuvant hormonal treatment in the cited study (less than half of patients [11]). Another study reported a higher 20-year prostate cancer mortality rate in lymph nodepositive patients who underwent radical prostatectomy and orchiectomy between 1966 and 1995 (42\% [12] vs. $29 \%$ in our study), possibly reflecting the poorer risk profile of patients partially treated in the pre-PSA era [12]. The 10 -year prostate cancer mortality rate of $18 \%$ in our sample was lower than that observed in a study investigating patients receiving both androgen deprivation and radiotherapy within 12 months after radical prostatectomy (23\%) [13], whereas another study reported a rate that was something lower than the 10 -year mortality rate (12.5\%) [14] in patients receiving both adjuvant treatment modalities. In lymph node-positive patients treated between 1987 and 2012 [15], the 20-year prostate cancer mortality rate was similar to that in our study (31\% [15] vs. $29 \%$ ), whereas the 20 -year competing mortality rate was higher (39\% [13] vs. 28\%) despite a lower age (mean age 64 years [15] vs. 65 years; median age 65 years [15] vs. 66 years). The authors developed a rather complex mod- 
el containing 4 weighed parameters (one of them, Gleason score, 3 -sided) in order to separate 3 balanced risk groups with 20 -year prostate cancer mortality rates of 19 , 34 , and $46 \%$ [15]. With our simple model containing only 2 dichotomous variables (Table 2, Fig. 1b), the separation of the 3 strata was even more distinct (4,27, and 44\%).

The huge differences in prostate cancer mortality between patients with positive lymph nodes at low and high risk of disease progression (at 10 years: 3 vs. $30 \%$, at 20 years: 5 vs. $44 \%$, Fig. 1) underline that retrospective comparisons assessing adjuvant radiotherapy in patients with positive lymph nodes $[13,14,16-18]$ should be considered with caution. Even slight enrichment of good risks in the radiotherapy subgroup (for instance because of an exclusion of patients with extensive lymph node involvement or with a postoperatively elevated PSA value) might pretend treatment-associated mortality differences. Without randomization it will hardly be possible to assess the effectivity of adjuvant radiotherapy for patients with positive lymph nodes.

This study has several limitations. There was no complete information of the application and the timing of adjuvant or deferred treatments like androgen deprivation or radiotherapy. Neoadjuvant hormonal treatment might have falsely increased the prostatectomy specimen Gleason score in some patients. Multiple surgeons and pathologists were involved in the treatment and the classification of the patients over a relatively long time period.

In conclusion, less than one third of patients with positive lymph nodes may be expected to die from prostate cancer within 20 years after radical prostatectomy. Mortality was determined by tumor biology, reflected by Gleason score and lymph node density; neither the year of surgery nor the number of removed lymph nodes was associated with outcome. In patients with a lymph node density below median $(<11.1 \%)$ and a Gleason score $<8$, the risk of dying from prostate cancer within 20 years after surgery was as low as $5 \%$.

\section{Disclosure Statement}

The authors declare that they have no conflicts of interest to disclose.

\section{References}

1 Mottet N, Bellmunt J, Bolla M, Briers E, Cumberbatch MG, De Santis M, et al. EAU-ESTRO-SIOG Guidelines on prostate cancer. Part 1: Screening, diagnosis, and local treatment with curative intent. Eur Urol. 2017 Apr;71(4):618-29.

2 Porcaro AB, De Luyk N, Corsi P, Sebben M, Tafuri A, Processali T, et al. Clinical factors predicting bilateral lymph node invasion in high-risk prostate cancer. Urol Int. 2017; 99(4):392-9.

3 Onkologie L. (Deutsche Krebsgesellschaft, Deutsche Krebshilfe, AWMF): Interdisziplinäre Leitlinie der Qualität S3 zur Früherkennung, Diagnose und Therapie der verschiedenen Stadien des Prostatakarzinoms, Langversion 5.0, 2018, AWMF Registernummer: 043/022OL, [Interdisciplinary guidelines of S3 quality for early detection, diagnosis and treatment of different stages of prostate cancer. Long version 5.0, 2018. Register number 043/022OL. Guidelines in German] (accessed February 26, 2019). Available from: http://www.leitlinienprogramm-onkolo-gie.de/leitlinien/prostatakarzinom/.

4 Mandel P, Kriegmair MC, Bogdan K, Boehm $\mathrm{K}$, Budäus L, Graefen M, et al. Association between lymph node counts and oncological outcomes in lymph node positive prostate cancer. Eur Urol Focus. 2017 Apr;3(2-3):24855.
5 Fossati N, Willemse PM, Van den Broeck T, van den Bergh RCN, Yuan CY, Briers E, et al. The benefits and harms of different extents of lymph node dissection during radical prostatectomy for prostate cancer: A systematic review. Eur Urol. 2017;72:84109.

6 Seiler R, Studer UE, Tschan K, Bader P, Burkhard FC. Removal of limited nodal disease in patients undergoing radical prostatectomy: long-term results confirm a chance for cure. J Urol. 2014 May;191(5):1280-5.

7 Stephenson AJ, Kattan MW, Eastham JA, Bianco FJ Jr, Yossepowitch O, Vickers AJ, et al. Prostate cancer-specific mortality after radical prostatectomy for patients treated in the prostate-specific antigen era. J Clin Oncol. 2009 Sep;27(26):4300-5.

8 Eggener SE, Scardino PT, Walsh PC, Han M, Partin AW, Trock BJ, et al. Predicting 15-year prostate cancer specific mortality after radical prostatectomy. J Urol. 2011 Mar;185(3):869_ 75.

9 Froehner M, Scholz A, Koch R, Hakenberg OW, Baretton GB, Wirth MP. Competing mortality contributes to excess mortality in patients with poor-risk lymph nodepositive prostate cancer treated with radical prostatectomy. Urol Int. 2012;89(2): $148-54$.

10 Messing EM, Manola J, Yao J, Kiernan M, Crawford D, Wilding G, et al.; Eastern Coop- erative Oncology Group study EST 3886. Immediate versus deferred androgen deprivation treatment in patients with node-positive prostate cancer after radical prostatectomy and pelvic lymphadenectomy. Lancet Oncol. 2006 Jun; 7(6):472-9.

11 Pierorazio PM, Gorin MA, Ross AE, Feng Z, Trock BJ, Schaeffer EM, et al. Pathological and oncologic outcomes for men with positive lymph nodes at radical prostatectomy: The Johns Hopkins Hospital 30-year experience. Prostate. 2013 Nov; 73(15): 1673-80.

12 Bhindi B, Rangel LJ, Mason RJ, Gettman MT, Frank I, Kwon ED, et al. Impact of radical prostatectomy on long-term oncologic outcomes in a matched cohort of men with pathological node positive prostate cancer managed by castration. J Urol. 2017 Jul;198(1): 86-91.

13 Zareba P, Eastham J, Scardino PT, Touijer K. Contemporary patterns of care and outcomes of men found to have lymph node metastases at the time of radical prostatectomy. J Urol. 2017 Nov; 198(5): 1077-84.

14 Touijer KA, Karnes RJ, Passoni N, Sjoberg DD, Assel M, Fossati N, et al. Survival outcomes of men with lymph node-positive prostate cancer after radical prostatectomy: A comparative analysis of different postoperative management strategies. Eur Urol. 2018 Jun;73(6):890-6. 
15 Moschini M, Sharma V, Zattoni F, Boorjian SA, Frank I, Gettman MT, et al. Risk stratification of $\mathrm{pN}+$ prostate cancer after radical prostatectomy from a large single institutional series with long-term followup. J Urol. 2016 Jun;195(6):1773-8.

16 Briganti A, Karnes RJ, Da Pozzo LF, Cozzarini C, Capitanio U, Gallina A, et al. Combi- nation of adjuvant hormonal and radiation therapy significantly prolongs survival of patients with pT2-4 $\mathrm{pN}+$ prostate cancer: results of a matched analysis. Eur Urol. 2011 May; 59(5):832-40.

17 Abdollah F, Karnes RJ, Suardi N, Cozzarini C, Gandaglia G, Fossati N, et al. Impact of adjuvant radiotherapy on survival of patients with node-positive prostate cancer. J Clin Oncol. 2014 Dec;32(35):3939-47.

18 Gupta M, Patel HD, Schwen ZR, Tran PT, Partin AW. Adjuvant radiation with androgen-deprivation therapy for men with lymph node metastases after radical prostatectomy: identifying men who benefit. BJU Int. 2019 Feb;123(2):252-60. 